\title{
O MAIS ALTO SOM DO SILÊNCIO: HISTÓRIA E MEMÓRIA DO XANGÔ ALAGOANO
}

RAFAEL, Ulisses Neves. Xangô rezado baixo: religião e política na Primeira República. São Cristóvão: Editora UFS; Maceió: EDUFAL, 2012. $277 \mathrm{p}$.

$D_{\text {ia }} 1$ de fevereiro de 2012: o governador de Alagoas, Teotônio Vilela Filho, assina um pedido de perdão a todas as comunidades de terreiros do seu estado pelas atrocidades que marcaram o dia $1^{\circ}$ de fevereiro de 1912, conhecido como a Quebra do Xangô ou Quebra de 1912. A assinatura foi feita no final de um cortejo popular que passou por diversos locais da capital alagoana, como a Praça d. Pedro II, a Rua do Sol até a Praça dos Martírios, cujo trecho é considerado importante ponto de confluência de terreiros de Maceió. Em seu discurso, Vilela Filho chamou atenção especial para a importância das recordações que ficaram ocultadas e silenciadas:

Nossa memória alagoana precisa ser revigorada com o resgate de lembranças escondidas, erroneamente varridas para baixo do tapete de penumbra do silêncio. Não podemos esquecer que 2012 marca o centenário do auge do período de persegui- ção aos praticantes dos cultos afro-brasileiros em Alagoas.

Um imenso substrato de imagens, memórias e paisagens estava em jogo naquele momento. A primeira metáfora vinha pelo registro da história. O Quebra de 1912 foi um acontecimento extraordinário de repressão às religiões de matriz africana no Brasil, que culminou com a invasão e destruição dos principais terreiros de Xangô da capital de Alagoas. Os terreiros foram invadidos pelos populares ligados aos sócios da Liga dos Republicanos Combatentes, uma espécie de milícia de capangas opositora do Partido Republicano de Alagoas, então chefiado por Euclides Malta, que se encontrava no exercício de seu terceiro mandato e à beira de eleger seu candidato nas eleições que se aproximavam.

A segunda imagem oriunda dessa história vem pela memória. Durante as primeiras décadas do século 
XX, pairou sobre o Xangô alagoano um enorme silêncio. Lembrando os conceitos de Murray Schafer, é possível dizer que houve, inclusive, uma sensível mudança na paisagem sonora de Maceió. ${ }^{1}$ Tambores calados e vozes emudecidas se traduziram na parca literatura antropológica sobre os chamados cultos afro-brasileiros de Alagoas. Esse silêncio é mais do que simbólico. Em 1939, o médico pernambucano Gonçalves Fernandes se referiu a um "candomblé do silêncio", em referência ao que ele chamava de "uma nova seita afro-brasileira, o xangô-rezado-baixo", como típico e característico dos terreiros de Maceió.

Tomando a história e a memória dessa dupla omissão sobre o Xangô de Alagoas, o antropólogo Ulisses Neves Rafael publicou, em 2012, o livro aqui resenhado. $\mathrm{O}$ autor começa com a etnografia da perseguição ao Xangô, na construção de um ciclo narrativo magistral que leva o leitor à compreensão do que foi o Quebra de 1912, dos mitos construídos em torno dessa legenda, do desinteresse acadêmico pelo tema, das incursões teóricas do autor para esclarecê-lo e da necessária revisão bibliográfica que o circunscreve.

O livro, no entanto, também é de história. Digamos que de uma história social e política da Primeira República no Nordeste Brasileiro.

Cf. R. Murray Schafer, A afinação do mundo, São Paulo: Unesp, 2001; R. Murray Schafer, $O$ ouvido pensante, São Paulo: Unesp, 1991.
Maneja com muita propriedade as múltiplas faces da famosa oligarquia dos Maltas de Alagoas, construindo um retrato pormenorizado de Euclides Malta, o líder político apelidado por Sílvio Romero, ainda em 1908, de oikocrata, familista primitivo e chefe da "casa reinante" das Alagoas. ${ }^{2}$ Advogado, oriundo de uma família de proprietários rurais, Euclides Malta foi uma espécie de "bacharel anacrônico", no dizer de Ulisses Rafael. O líder político era, afinal, um misto de jovem bacharel urbano que exaltava sua personalidade individual como modelo de valor próprio, superior às contingências da política. Porém, ao mesmo tempo, este mesmo personagem das gestas de poder alagoano revelou ser ponte entre as antigas estruturas locais, comandadas por coronéis semianalfabetos, e a sua própria geração de bacharéis emergentes e muito bem instruídos, que circulava no entorno dessa classe de latifundiários e donos de engenhos. Mais que isso, Euclides Malta criou um paradigma para as administrações futuras em Alagoas, na medida em que não somente foi modelo local para a construção da República, como também para o tipo de política oligárquica que misturava o bacharelismo, o coronelismo, o trabalho rural e o controle dos votos.

Uma das faces da política des-

\footnotetext{
2 Sílvio Romero, Provocações e debates (contribuição para o estudo do Brazil social), Porto: Lello \& Irmãos, 1910, pp. 401-16.
} 
se tempo foi a reaproximação dos governos com as instituições religiosas, especialmente com a Igreja Católica, que havia se separado do Estado no final do Império. Em todo o Brasil, no entanto, a Igreja estava nas entranhas do poder. Mas as religiões afro-brasileiras em Alagoas foram toleradas, e o poder público, ao tempo dos Maltas, parece ter sido bastante complacente com o funcionamento dos terreiros em Maceió, dando pouca atenção inclusive às queixas dos incomodados com as práticas religiosas e culturais de tais casas. A história do Quebra de 1912 revela, portanto, os meandros da aproximação e da benevolência do governador com aquelas práticas religiosas, além do que paira na memória da cidade: as frequentes visitas que o chefe do Estado fazia às mães e pais de santo para que consultassem os orixás sobre os destinos de sua carreira eleitoral. Ulisses Rafael conta, com detalhes e a argúcia etnográficos, a história do "papa do Xangô alagoano" e suas incursões pelo campo religioso.

Mas de onde vem esse Xangô de Alagoas? Por que a vida cultural e religiosa de negros esteve tão ligada à política local? Uma digressão foi necessária no livro de Ulisses Rafael para responder a essas e outras questões correlatas. Primeiramente, foi essencial refletir a respeito da vida social dos negros em Alagoas, mas, além disso, sobre a miopia acadêmica aliada a um discurso conservador, que outro autor, Dirceu Lindoso, já havia chamado de "historiografia da dominação sesmeiro-escravista". ${ }^{3}$ Os historiadores locais, de Thomas Espíndola a Jayme de Altavilla, puseram-se a manter, segundo o juízo de Rafael, "a tradição ilustrativa ao tratar dos principais eventos da história de maneira superficial e pouco crítica” (p. 151). Porém, apesar disso, há uma literatura com certa influência do modernismo, e que, em parte, buscava valorizar aspectos anteriormente detratados da cultura negra no Brasil que vicejou em Alagoas. Alfredo Brandão, Manoel Diégues Júnior, Abelardo Duarte estabeleceram as bases da pesquisa do folclore negro em Alagoas, especialmente nas áreas rurais, onde predominou o cultivo da cana-de-açúcar. Restou uma lacuna acerca do cotidiano do negro na cidade, que o autor procurou recuperar por meio de crônicas e romances escritos nas duas primeiras décadas do século XX, especialmente na obra de Félix Lima Júnior.

Além da historiografia, do folclore e da literatura locais, outras fontes campeiam na obra de Ulisses Rafael, como as notícias de jornais, verdadeira crônica da repressão, das representações e dos registros visuais sobre as religiões afro-alagoanas. As imagens são mais importantes que a sua compreensão. Quer dizer, o impacto dos termos é mais meritório que seus significados. "Zum-

\footnotetext{
3 Dirceu Lindoso, A utopia armada: rebelião de pobres nas matas do Tombo Real, Rio de Janeiro: Paz e Terra, 1983, pp. 34-5.
} 
baias de adufes", “danças macabras”, "carapuças vermelhas", "jovens obsedadas", "algaravia africana". Subjaz nesse jogo de palavras um conteúdo apreendido pelos sentidos, pela imaginação, pela memória e pelo pensamento social da época a respeito do que hoje podemos chamar, sob outro ponto de vista, de herança cultural dos negros brasileiros. Mas, se jornais divulgavam o cenário da religião, também havia espaço para o dia a dia da casa de detenção, porque o autor busca reconstituir alguns aspectos sobre a prisão e o encarceramento de negros em Maceió, por meio de dados estatísticos, informações etárias, as marcas da cor da pele e uma tentativa de análise da ocupação e do registro profissional dos negros nos registros da polícia. E, se o assunto é o viver na cidade, os jornais também se apresentam com a principal fonte sobre o que, no limiar do século XX, ainda se chamava de "folga de negro", referência ao carnaval popular. Rafael percebeu, por meio das festas de Momo, como a condição social de negros e pobres deu o tom dos conflitos, aproximações e negociações de classe em Alagoas. Diz ele que

[...] o elemento que conspira contra esses foliões não é mais a cor, e sim, a sua baixa condição social, o que no Brasil, corresponde desde sempre a uma origem étnica marginal, à qual os não brancos sempre estiveram associados (p. 205).

Por fim, no quarto e último capí- tulo, o autor analisa a história da perseguição ao Xangô alagoano, com base na atuação da citada Liga dos Republicanos Combatentes, criada meses antes do Quebra de 1912. A formação dessa milícia paramilitar é também um traço característico da estrutura de dominação política da República Velha, mostrando a conexão entre diferentes segmentos da sociedade que circulam entre o religioso e o profano, em cujos ambientes transitou, se nutriu e se desenvolveu. No caso dessa liga em especial, ressalta-se o papel de seu "anjo da guarda", Manoel Luiz da Paz, cuja fama de truculento, brigão e autoritário atraiu pessoas das camadas sociais mais baixas da população em busca de integração e ascensão sociais. Contudo, é complexo e cheio de ambiguidades o episódio do conflito entre "combatentes" e "xangozeiros" em Maceió, na medida em que uma das especificidades do quebra-quebra é que resultou de uma campanha deflagrada numa curta jornada de poucos dias, promovendo a destruição temporária de quase todas as casas de culto da capital e redondezas, sob o comando de uma associação civil, a Liga dos Republicanos Combatentes, que foi, ao mesmo tempo, responsável também pelo desmantelamento das próprias instituições oficiais alagoanas da época, já que o próprio Batalhão Policial foi dissolvido oficialmente por decreto, no mesmo dia em que se iniciaram as invasões dos terreiros,

[...] fícando o serviço de policia- 
mento da capital e de algumas cidades do interior a cargo de uma guarnição federal e de alguns homens de confiança do governador interino, Macário Lessa (p. 262).

Em suma, os sons do silêncio do Xangô trazem muito mais que um devaneio poético para a história e para a antropologia das religiões afro-brasileiras. Essa imagem de atabaques silenciados pela repressão traz consigo - pensando na obra de Bachelard sobre a força dos sons na imaginação do movimento - ${ }^{4}$ uma história impressionante em pelo menos quatro pontos, que Ulisses Rafael esquadrinha habilmente. O primeiro é que a perseguição religiosa esteve sempre relacionada com os conflitos e querelas políticas das oligarquias alagoanas. O segundo é que a perseguição não foi pontual,

4 Cf. Gaston Bachelard, L'air et les songes: essai sur l'imagination du movement, Paris: José Corti, 1943. Ver, também, Norberto Perkoski, "Os sons do silêncio: um devaneio poético”, Letras de Hoje, n. 41 (2006), pp. 83-92. realizada contra um individuo ou uma casa de culto, mas contra quase todas as manifestações religiosas associadas às matrizes africanas. $\mathrm{O}$ terceiro ponto diz respeito à arbitrariedade do feito, no qual a figura do Estado e suas instituições estiveram totalmente ausentes, acentuando o papel do mandonismo local na sociedade brasileira da época. O quarto e último ponto talvez seja o mais brutal e também, de certo modo, o principal sentido do livro de Ulisses Neves Rafael. O silêncio que paira sobre o Xangô rezado baixo e seus desdobramentos na história de Alagoas, segundo o autor deste livro, chega a ser constrangedor. Porém, a obra que o leitor terá oportunidade de ler trata de romper com esse silêncio. O Xangô reza alto neste livro de muitas histórias, memórias e sonoridades das terras alagoanas.

Aldrin Moura de Figueiredo aldrinfigueiredo@uol.com.br Universidade Federal do Pará 